\title{
Interculturality Between Formal and Non-formal Education in Italy
}

Massimiliano Fiorucci 


\title{
Interculturality Between Formal and Non-formal Education in Italy
}

\author{
Massimiliano Fiorucci ${ }^{a^{*}}$ \\ ${ }^{a}$ Department of Education, Roma Tre University, Via del Castro Pretorio, 20 - 00185 Rome, Italy \\ *Corresponding author: massimiliano.fiorucci@ uniroma3.it
}

\begin{tabular}{l} 
Abstract \\
\hline \multicolumn{1}{c}{ Keywords: } \\
interculturality, \\
immigration, educational \\
and cultural needs \\
Zusammenfasung
\end{tabular}

Schlüsselworte:

Interkulturalität;

Immigration; Bildungs- und

Kulturbedürfnisse
The paper focuses on the educational and cultural needs of adult migrants, in order to overcome a uniquely paternalistic view of immigration. Focusing on the educational and cultural needs affects, in fact, the quality of the experience of integration. Within this proposal the adoption of an intercultural mediation strategy can play an important role also with reference to the context of cultural services.
Das vorliegende Papier konzentriert sich auf die Bildungs- und Kulturbedürfnisse erwachsener Migranten, um eine einzigartig paternalistische Sichtweise der Einwanderung zu überwinden. Die Konzentration auf die Bildungs- und Kulturbedürfnisse betrifft in der Tat die Qualität der Erfahrung der Integration. Innerhalb dieses Vorschlags kann die Annahme einer interkulturellen Vermittlungsstrategie auch in Bezug auf den Kontext kultureller Dienstleistungen eine wichtige Rolle spielen.

\section{Introduction}

From a general point of view, it can be affirmed that two processes today have a significant impact on society and, consequently, on education: the strong and pervasive changes in technology and the migratory processes that affect the entire planet in different ways and forms.

In this paper we will attempt to re-read the situation of the multicultural society in Italy, in light of a broader interpretation of the notion of non-formal education understood in the sense of natural education: education that happens without anyone intentionally taking part.

\section{About the migration processes in Italy}

With reference to the migration processes underway and, in particular, to the problems posed by the presence of immigrants in today's society, it can be said that regardless of what school or training one does or does not attend, dynamic and pervasive educational processes are already in place. When people who belong to different cultures meet, fields of tension are inevitably produced- characterized by integration and distinction, fusion and separation, inclusion and exclusion, etc. What happens then? To answer this question, it may be useful to refer to the notion of lifelong education. "The notion of lifelong education can be useful if it is taken to mean 'ongoing natural education in progress': with which we would highlight that the 'social contexts' of life and work educate positively, continuously, and affect our values, structure our habits, and induce our behaviors. What is particular about these educational processes is that they take place in the form of 'hidden curricula' and that little or no widespread social control is exercised over them. This has effects on everyone. As regards immigrant workers in Italy, it follows that, in general, the only educators they meet, real ones, who actually 'teach' their values and behaviors, are those with whom immigrants are closest in contact with: police officers, landlords, bosses, passers-by and sometimes, if they are lucky, a teacher, a trade unionist, a service provider, or a volunteer. [...] Since the relationships between subjects are always endowed with both socioaffective and cognitive formative efficacy, in the sense that they provide information, transmit knowledge and suggest behavior, it must be inferred that, in Italy, not only are educational projects that intentionally pursue the goal of a multicultural society entirely absent, but there are, on the contrary, projects that, in more or less hidden forms, operate in a diametrically opposite way" (Susi, pp. 28-29). 


\section{Work - at the center of the migration path in Italy}

It can therefore be stated that the participation of immigrants in society and the Italian labor market to a large extent shows the characteristics of what was defined by Maurizio Ambrosini as subordinate integration. Immigrants are accepted in the workplace on the basis of the idea that the role assigned to them is to do the jobs which Italians no longer aspire to do, with the implicit corollary that, if more interesting occupations become available, Italians have an indisputable right of priority. However, work is at the center of the migration path. An essential role in the meeting between Italian labor demand and immigrant supply is played by so-called "ethnic networks", i.e. the networks of support and mutual help between immigrant relatives and compatriots. In a market that is difficult to analyze and in some cases deregulated, the spread of information relating to job vacancies, sponsorship, and socialization at work happens through contact with people linked by personal relationships and emotional bonds. Many immigrants point out that often an Italian citizen must introduce them because otherwise employers may be wary. The intersection between supply and demand of labor almost always passes, therefore, through informal channels. Often there is no possibility for immigrants to "become a professional" and immigrant workers often move and change employers. Migrants face a situation of poor social and professional upward mobility. Immigrants find themselves in a system of "arrested professional growth" and even those with high levels of education undergo a process of decline and professional downgrading in Italy. Immigrants, in fact, are not such weak individuals (they often have solid professional experience and medium to high educational qualifications), but they become so in the Italian society and labor market that reserve the lowest positions for them. There is a gap between human capital possessed and professional levels of integration that serves neither the direct stakeholders nor, in the medium to long-term, the host country. What may appear to be successful integration, often, in the eyes of the person concerned, feels unsatisfactory and is seen as an unsuccessful fall-back. The result is a subjective experience that, especially in the most prepared and efficient individuals at work, takes on the tones of frustration, dissatisfaction and, in some cases, condemnation.

There is a sort of "ghettoization" for immigrants who seem forced to remain anchored in the lower segments of the labor market. Furthermore, "in the frame of mind of employers and more general of public opinion, provenance [immigrants' national origin] quickly becomes an indicator of a worker's ability to enter into certain occupational areas" (Caritas-Migrantes, 2006, p. 48). This is how the socalled "ethnic specializations" are formed, which are often recorded in local labor markets and which, in some cases, imprison workers by pre-defining their fields of integration. It is necessary to work to break these "vicious circles" and release the positive energies that immigration brings with it. Such a change will be possible not only through targeted training activities, but above all through strong political action that contributes to the evolution of the demands of employers and entrepreneurs.

It should be noted, however, that in some Italian situations, while relatively few in number, numerous initiatives have been implemented and interesting projects have been tested in this direction. Their aims include integration through orientation, balance of competences, insertion and job reintegration, and projects that help foreigners through linguistic literacy courses with particular attention to the most vulnerable people, especially women, who often rejoin their husbands later, and have no opportunity to enter the community.

However, there is a lack of information on these initiatives reaching potentially interested foreign citizens. In this regard, greater information and awareness-raising action through the media (television, radio, newspapers, etc.) and through less traditional channels (meeting places, immigrant associations, etc.) would also be useful.

Furthermore, it seems that there is limited willingness on the part of foreign citizens to invest in their own training, also because it is often difficult and tiring after a "hard" day's work, to take part in a training course that may also take place very far from one's home.

As regards the possibility of involving immigrants in their direct training actions, it is important to underline that:

1. it is essential to launch a public information and awareness campaign, based on the consideration that there is no communication between the existing offers (in some cases plentiful) and the interested parties;

2. the coordination of efforts must be strengthened in the sense of both a network system and the organization of supply chains - the lack of which prevents optimal use of resources;

3. the existing supply often proposes the same methods (organizational, methodological and didactic) that have contributed to determining the processes of removal and exclusion from the training courses.

The main critical elements that characterize the situation of immigrants, which have emerged in the context of specific research on these topics, can be identified in the following points (The considerations made refer to results emerging from studies conducted by the author of this article. See in particular: M. Fiorucci, The analysis of the training needs of the adult population in Municipalities I and IX, in "Lifelong learning: the supply and demand of training in the Municipalities I and IX", vol. 2, FSE Project "Launch of the city system for Adult Education and the establishment of Local Committees", Department Office for Educational and School Policies, Municipality of Rome, Rome 2007, pp. 4-84; M. Fiorucci, W. Bonapace (editor), Immigration: integration dynamics and paths of inclusion in Valle d'Aosta, Regional Institute of Research of Valle d'Aosta, Aosta 2007): 
- poor control of the Italian language in the initial phase of integration;

- bureaucratic and legal impediments often linked to their legal status;

- different perspectives related to country of origin and family status strongly influence the migration patterns and condition the "migratory plans" (very short, short, medium and long term) of the individuals;

- limited time (impossible to reconcile education time with time spent at work and at home);

- the lack of a family network to compensate for the lack of care services (a problem of immigrant mothers who are unable to attend any educational activities due to lack of available child care).

\section{Interculturality in formal and non-formal contexts}

Considering the relationship between immigrants and host societies more generally, and in light of the different "levels of belonging that the current system of citizenship provides, of the three elements (civil, political and social) that describe them, according to the well-known outline of Marshall, belonging to a society, in concrete situations, there is 'the attribution of certain rights to immigrants that form the package of citizenship, but not others' (Sgritta, 1993, p. 12). It is above all in the political sphere that the separation between citizens and immigrants is most evident and frequent; between individuals with full rights and those excluded from participation in the electoral process, the elaboration of policies and the implementation of administrative and governmental decisions which, all too often, affect them directly. In developed countries, legal immigrants enjoy conditions substantially similar to the rest of the population in civil and social spheres. But even in these cases, where the law, as in Italy, ensures equality of civil rights and access to public services, it remains to be seen whether and to what extent this legal recognition is able to allow for effective equality in living conditions and utilization of the various opportunities offered by society. Ultimately, there are two sides to the problem: one regulatory, in the recognition of the same rights as citizens, and the other, in verifying the gap that separates real conditions of immigrants from those of other groups in society. From this perspective, the immigrant situation will move from one extreme, with exclusion, due to legal or social discrimination, to another, that of full integration, as a consequence of effective equality of opportunities and conditions with the local population" (Bonifazi, 2007, pp. 216-217).
Immigrants in Italy enjoy what can be defined as relative citizenship. It is perhaps not enough to see the different positions present within society exclusively in terms of racism or lack thereof: this is a dichotomy that is in some ways overly reductive, given that "the range of positions is, in fact, much broader and that positions on immigration can be determined, even on an exclusive or predominant basis, based on considerations of a completely different nature; for example, the advantages or disadvantages (real or presumed) that the presence of foreign workers can present to individuals or the different social groups to which they belong. In fact, the way in which the local population sees and rationalizes immigrants, or outsiders, does not depend on deep psychological concepts or on the existence or not of ethnic prejudices alone, but also on how these 'outsiders' move (or are thought to move) within society, the conflicts that have brought about their presence, how the situation is presented by the mass media and political pundits, and by how the public administration manages the phenomenon.

Ultimately, an approach that seeks to take into account all the aspects linked to immigration appears more worthwhile, since it takes the examination of the problem to a more direct level, better rationalized and certainly more immediately applicable at the time of political and administrative implementation" (Bonifazi, 2007, pp. 196197).

Local authorities, public services (educational, social, health, etc.), trade unions, non-profits and associations, each in their own way, over the last few years have all promoted policies, implemented projects and applications, and developed practices which, while not always innovative, have nevertheless highlighted how it is increasingly necessary to work both on the side of interculturality and towards the recognition of equal opportunities between natives and foreigners. The "intercultural opening of services, in addition to aiming for practical goals, also seeks to awaken the awareness that in everyday professional life we must actively confront interculturality, proving that we are ready to deal with ways of seeing that are also completely different from our own. A process with positive effects for all, both locals and foreigners" (Luatti, 2006, p. 7).

The context of the emerging Italian situation is one of great variety in terms of local policies, intercultural resources, and innovative practices. Alongside the structures and services that have been involved in migration from the very beginning, and where the theme of interculturality has had the chance to soak in, there are other services that, due to resistance and rigidity, face longer delays on the path to adaptation of operating methods to try to respond to increasingly complex users. These services, however, need to be adequately supported (in both economic and staffing terms) by the Government and institutions to improve their responses and to act in the main 
reference areas of integration dynamics (economic, social, cultural, political and demographic). For the immediate future it is a question of improving and reinforcing what has already been achieved, passing from a reactive vision (of response to emergencies and essential needs) to a proactive perspective, which meets people (in their homes and at work) as a whole, through a system of services throughout the territory, guaranteeing the right of citizenship while addressing the cultural needs and active participation of the immigrant population in view of "full integration".

Today, more than 40 years after Italy's transformation into a country of immigration, it is necessary to take a different view of individuals of foreign origin no longer as bearers of needs, but as bearers of rights. The central aspect today is represented by intercultural dialogue, but as we have said, dialogue requires conditions of possibility, a condition of relational symmetry that is currently nonexistent, and that is the possibility of expressing one's own subjectivity, one's own needs, one's desires, interests and equal rights.

Interculturality, to avoid remaining simply rhetorical, is essentially a political task, intertwined as it is with cultural conflicts, socio-economic differences, diversity management, migrant rights, democratic development and the promotion of equality of rights between all citizens. There is intercultural dialogue if there is a de facto symmetry between migrants and non-migrants: today there is a condition of relative citizenship of migrants who pay the price of "subordinate integration". This condition undermines the notion of dialogue, making it clear that it is necessary to overcome both "miserable" and "utilitarian" visions of migration, that is, two reductionist visions that move between paternalism and economic functionalism and that tend to reduce migrants to predefined categories by the host countries. Therefore, hierarchical, assimilationist and asymmetrical visions must be overcome in order to assume a co-educational perspective open to the direct presence of migrant cultures, inaugurating an innovative path of "dialog-based education" that is built together, through relationships founded on the basis of equality, reciprocity and responsibility. This will be possible through action aimed at:

- honoring the linguistic and cultural heritage which migrants bring, giving citizenship to multilingualism as a resource, supporting and expanding the associations of migrant communities as agents of intercultural mediation and overcoming the concept that cultures and identities are static realities, on the one hand, or folklore, on the other. Too often, in fact, misinterpreted intercultural education is conditioned by an allegorical, essentialist and relativistic vision of glorification of cultural differences as such, rather than by a constructivist view of cultural diversity and the search for citizenship and social cohesion. Cultural diversity can only be conceived in terms of identity (hybrid and mutable) built socially through social interaction and not as naturally inherent (inevitable and unchanging) to a person or a group. The philosopher Kenan Malik clearly highlighted the risks of an essentialist vision of culture and identity: "Multiculturalists and forerunners of the clash of civilizations share the basic assumptions about the nature of culture, identity and difference. Both consider the main social divisions as the result of a cultural matrix or civilization. Both view cultures, or civilizations, as homogeneous entities. Both insist on the crucial importance of cultural identity and the preservation of this identity. Both perceive the conflicts emerging from non-negotiable values as unresolvable "(Malik, 2016, p. 86);

- giving visibility to the educational and cultural needs of migrants, not just to their basic needs (reception), focusing on the theme of intercultural mediation as a perspective that also takes into account the role of the socalled "second generation" of immigration. Here we consider the question of the scholastic, educational and professional orientation of this "second generation" that represents not only a crucial part of the migration phenomenon, but also a challenge for social cohesion and a factor of transformation of Italian society. Dealing with the "second generation" means first and foremost thoroughly investigating how the social composition of a country is being redefined. Italy, for example, is a country historically characterized by profound diversity, and within which regional and local identifications have played a very important role. It is with the "second generation" that some fundamental obstacles to social integration come to the fore that were hidden or postponed for first-generation immigrants, who were in a homecoming phase. In the context of immigrant populations, the very birth and socialization of the "second generation" represents a decisive moment for the awareness of their status as minorities now established in a different context from that of the original society. With them, needs arise for the definition, re-elaboration and transmission of their cultural heritage, as well as models of family education. Therefore, these young people live in a condition of "double identity" or "double belonging" and must be prevented from turning into a "double absence" (Sayad). The young people of the "second generation" are "natural cultural mediators", but there must be the conditions for their support and empowerment in schools, associations and society, starting from the juridical recognition of Italian citizenship by reforming the obsolete legislation founded on the right of blood;

- strengthen networks between schools, adult education centers, and community centers intended as connection spaces that favor critical reflection on educational practices and on the development and implementation of intercultural activities that are not only addressed to migrants and the "second generation", but to the whole population in a real intercultural perspective, first of all rethinking school and education as a privileged place 
for intercultural mediation. School is one of the key elements of a process of integration that connects the scholastic success of the children of immigrants, the professional and social integration of families, as well as being the "place" given to cultural differences in our society. To facilitate the transition from a situation of multiculturality, with the simple coexistence between different cultures, to an authentic situation of integration, acceptance and exchange, schools must promote meeting and favor situations of connection with others. The intercultural approach is an indispensable way to respect and value diversity in search of common values that allow us to live together. This new vision of relationships between people who belong to different cultures should modify and transform the structure of school and teaching organizations, teaching and training methods, assessment methods, relationships between teachers, pupils and families in and outside of school, and provide a perspective from which to approach knowledge and the disciplines. Intercultural education is one of the indispensable tools for facing the challenge of a multicultural society through the construction of paths of recognition of pluralism and diversity in reciprocity. In essence, it is now clear that today it is impossible to speak of integration without more consciously encouraging the goal of bringing about a new reality - an intercultural reality - within which schools, institutions and the Italian society all have to face one another. In doing so, they must question the methods and knowledge with which they examine their relationships with the more than 5 million migrant citizens who today live, work, study, grow and age in our country.

Intercultural education requires a constant commitment in schools and at all levels of society within the framework of lifelong learning processes of individuals and communities. This approach is neither natural nor obvious and, on the contrary, represents an intentional educational project and a process that must be consciously carried out day by day and that requires attention and competence on the part of all participants. "Intercultural education is part of the great tradition of Italian democratic pedagogy and has among its main objectives social justice and equal opportunity regardless of an individual's history or origin. Intercultural strategies avoid separating individuals into autonomous and impermeable cultural worlds, instead promoting debate, dialogue and even mutual transformation, to make coexistence possible and to face, with the tools of pedagogy, the conflicts that may arise" (Fiorucci, Pinto Minerva, Portera, 2017: 618).

An intercultural perspective and ingenuity represent indispensable assets for an education adapted to the times, capable of educating people aware that they are living in a global and complex world, where the encounter with cultural differences is now the norm.

From a general point of view, it can be affirmed that two processes today have a significant impact on society and, consequently, on education: the strong and pervasive changes in technology and the migratory processes that affect the entire planet in different ways and forms.

In this paper we will attempt to re-read the situation of the multicultural society in Italy, in light of a broader interpretation of the notion of non-formal education understood in the sense of natural education: education that happens without anyone intentionally taking part.

With reference to the migration processes underway and, in particular, to the problems posed by the presence of immigrants in today's society, it can be said that regardless of what school or training one does or does not attend, dynamic and pervasive educational processes are already in place.

It can be stated that the participation of immigrants in society and the Italian labor market to a large extent shows the characteristics of what was defined by Maurizio Ambrosini as subordinate integration. Immigrants are accepted in the workplace on the basis of the idea that the role assigned to them is to do the jobs which Italians no longer aspire to do, with the implicit corollary that, if more interesting occupations become available, Italians have an indisputable right of priority. However, work is at the center of the migration path. An essential role in the meeting between Italian labor demand and immigrant supply is played by so-called "ethnic networks", i.e. the networks of support and mutual help between immigrant relatives and compatriots. In a market that is difficult to analyze and in some cases deregulated, the spread of information relating to job vacancies, sponsorship, and socialization at work happens through contact with people linked by personal relationships and emotional bonds. Many immigrants point out that often an Italian citizen must introduce them because otherwise employers may be wary. The intersection between supply and demand of labor almost always passes, therefore, through informal channels. Often there is no possibility for immigrants to "become a professional" and immigrant workers often move and change employers. Migrants face a situation of poor social and professional upward mobility. Immigrants find themselves in a system of "arrested professional growth" and even those with high levels of education undergo a process of decline and professional downgrading in Italy. Immigrants, in fact, are not such weak individuals (they often have solid professional experience and medium to high educational qualifications), but they become so in the Italian society and labor market that reserve the lowest positions for them. There is a gap between human capital possessed and professional levels of integration that serves neither the direct stakeholders nor, in the medium to longterm, the host country. What may appear to be successful integration, often, in the eyes of the person concerned, feels unsatisfactory and is seen as an unsuccessful fall-back. The result is a subjective experience that, especially in the most prepared and efficient individuals at work, takes on the 
tones of frustration, dissatisfaction and, in some cases, condemnation.

There is a sort of "ghettoization" for immigrants who seem forced to remain anchored in the lower segments of the labor market. Furthermore, "in the frame of mind of employers and more general of public opinion, provenance [immigrants' national origin] quickly becomes an indicator of a worker's ability to enter into certain occupational areas" (Caritas-Migrantes, 2006, p. 48). This is how the socalled "ethnic specializations" are formed, which are often recorded in local labor markets and which, in some cases, imprison workers by pre-defining their fields of integration. It is necessary to work to break these "vicious circles" and release the positive energies that immigration brings with it. Such a change will be possible not only through targeted training activities, but above all through strong political action that contributes to the evolution of the demands of employers and entrepreneurs.

\section{Practical possibilities to involve immigrants in training actions}

It should be noted, however, that in some Italian situations, while relatively few in number, numerous initiatives have been implemented and interesting projects have been tested in this direction. Their aims include integration through orientation, balance of competences, insertion and job reintegration, and projects that help foreigners through linguistic literacy courses with particular attention to the most vulnerable people, especially women, who often re-join their husbands later, and have no opportunity to enter the community.

However, there is a lack of information on these initiatives reaching potentially interested foreign citizens. In this regard, greater information and awareness-raising action through the media (television, radio, newspapers, etc.) and through less traditional channels (meeting places, immigrant associations, etc.) would also be useful.

Furthermore, it seems that there is limited willingness on the part of foreign citizens to invest in their own training, also because it is often difficult and tiring after a "hard" day's work, to take part in a training course that may also take place very far from one's home.

As regards the possibility of involving immigrants in their direct training actions, it is important to underline that:

1. it is essential to launch a public information and awareness campaign, based on the consideration that there is no communication between the existing offers (in some cases plentiful) and the interested parties;

2. the coordination of efforts must be strengthened - in the sense of both a network system and the organization of supply chains - the lack of which prevents optimal use of resources;
3. the existing supply often proposes the same methods (organizational, methodological and didactic) that have contributed to determining the processes of removal and exclusion from the training courses.

The main critical elements that characterize the situation of immigrants, which have emerged in the context of specific research on these topics (The considerations made refer to results emerging from studies conducted by the author of this article. See in particular: M. Fiorucci, The analysis of the training needs of the adult population in Municipalities I and IX, in "Lifelong learning: the supply and demand of training in the Municipalities I and IX", vol. 2, FSE Project "Launch of the city system for Adult Education and the establishment of Local Committees", Department Office for Educational and School Policies, Municipality of Rome, Rome 2007, pp. 4-84; M. Fiorucci, W. Bonapace (editor), Immigration: integration dynamics and paths of inclusion in Valle d'Aosta, Regional Institute of Research of Valle d'Aosta, Aosta 2007) can be identified in the following points:

- poor control of the Italian language in the initial phase of integration;

- bureaucratic and legal impediments often linked to their legal status;

- different perspectives related to country of origin and family status strongly influence the migration patterns and condition the "migratory plans" (very short, short, medium and long term) of the individuals;

- limited time (impossible to reconcile education time with time spent at work and at home);

- the lack of a family network to compensate for the lack of care services (a problem of immigrant mothers who are unable to attend any educational activities due to lack of available child care).

Considering the relationship between immigrants and host societies more generally, and in light of the different "levels of belonging that the current system of citizenship provides, of the three elements (civil, political and social) that describe them, according to the well-known outline of Marshall, belonging to a society, in concrete situations, there is 'the attribution of certain rights to immigrants that form the package of citizenship, but not others' (Sgritta, 1993 , p. 12). It is above all in the political sphere that the separation between citizens and immigrants is most evident and frequent; between individuals with full rights and those excluded from participation in the electoral process, the elaboration of policies and the implementation of administrative and governmental decisions which, all too often, affect them directly. In developed countries, legal immigrants enjoy conditions substantially similar to the rest of the population in civil and social spheres. But even in these cases, where the law, as in Italy, ensures equality of civil rights and access to public services, it remains to be 
seen whether and to what extent this legal recognition is able to allow for effective equality in living conditions and utilization of the various opportunities offered by society.

Ultimately, there are two sides to the problem: one regulatory, in the recognition of the same rights as citizens, and the other, in verifying the gap that separates real conditions of immigrants from those of other groups in society. From this perspective, the immigrant situation will move from one extreme, with exclusion, due to legal or social discrimination, to another, that of full integration, as a consequence of effective equality of opportunities and conditions with the local population" (Bonifazi, 2007, pp. 216-217). Immigrants in Italy enjoy what can be defined as relative citizenship. It is perhaps not enough to see the different positions present within society exclusively in terms of racism or lack thereof: this is a dichotomy that is in some ways overly reductive, given that "the range of positions is, in fact, much broader and that positions on immigration can be determined, even on an exclusive or predominant basis, based on considerations of a completely different nature; for example, the advantages or disadvantages (real or presumed) that the presence of foreign workers can present to individuals or the different social groups to which they belong. In fact, the way in which the local population sees and rationalizes immigrants, or outsiders, does not depend on deep psychological concepts or on the existence or not of ethnic prejudices alone, but also on how these 'outsiders' move (or are thought to move) within society, the conflicts that have brought about their presence, how the situation is presented by the mass media and political pundits, and by how the public administration manages the phenomenon.

Ultimately, an approach that seeks to take into account all the aspects linked to immigration appears more worthwhile, since it takes the examination of the problem to a more direct level, better rationalized and certainly more immediately applicable at the time of political and administrative implementation" (Bonifazi, 2007, pp. 196197).

Local authorities, public services (educational, social, health, etc.), trade unions, non-profits and associations, each in their own way, over the last few years have all promoted policies, implemented projects and applications, and developed practices which, while not always innovative, have nevertheless highlighted how it is increasingly necessary to work both on the side of interculturality and towards the recognition of equal opportunities between natives and foreigners. The "intercultural opening of services, in addition to aiming for practical goals, also seeks to awaken the awareness that in everyday professional life we must actively confront interculturality, proving that we are ready to deal with ways of seeing that are also completely different from our own. A process with positive effects for all, both locals and foreigners" (Luatti, 2006, p. 7).
The context of the emerging Italian situation is one of great variety in terms of local policies, intercultural resources, and innovative practices. Alongside the structures and services that have been involved in migration from the very beginning, and where the theme of interculturality has had the chance to soak in, there are other services that, due to resistance and rigidity, face longer delays on the path to adaptation of operating methods to try to respond to increasingly complex users. These services, however, need to be adequately supported (in both economic and staffing terms) by the Government and institutions to improve their responses and to act in the main reference areas of integration dynamics (economic, social, cultural, political and demographic). For the immediate future it is a question of improving and reinforcing what has already been achieved, passing from a reactive vision (of response to emergencies and essential needs) to a proactive perspective, which meets people (in their homes and at work) as a whole, through a system of services throughout the territory, guaranteeing the right of citizenship while addressing the cultural needs and active participation of the immigrant population in view of "full integration".

Today, more than 40 years after Italy's transformation into a country of immigration, it is necessary to take a different view of individuals of foreign origin no longer as bearers of needs, but as bearers of rights. The central aspect today is represented by intercultural dialogue, but as we have said, dialogue requires conditions of possibility, a condition of relational symmetry that is currently nonexistent, and that is the possibility of expressing one's own subjectivity, one's own needs, one's desires, interests and equal rights.

\section{Conclusions}

Interculturality, to avoid remaining simply rhetorical, is essentially a political task, intertwined as it is with cultural conflicts, socio-economic differences, diversity management, migrant rights, democratic development and the promotion of equality of rights between all citizens. There is intercultural dialogue if there is a de facto symmetry between migrants and non-migrants: today there is a condition of relative citizenship of migrants who pay the price of "subordinate integration". This condition undermines the notion of dialogue, making it clear that it is necessary to overcome both "miserable" and "utilitarian" visions of migration, that is, two reductionist visions that move between paternalism and economic functionalism and that tend to reduce migrants to predefined categories by the host countries. Therefore, hierarchical, assimilationist and asymmetrical visions must be overcome in order to assume a co-educational perspective open to the direct presence of migrant cultures, inaugurating an innovative path of "dialog-based education" that is built together, through relationships founded on the basis of equality, 
reciprocity and responsibility. This will be possible through action aimed at:

- honoring the linguistic and cultural heritage which migrants bring, giving citizenship to multilingualism as a resource, supporting and expanding the associations of migrant communities as agents of intercultural mediation and overcoming the concept that cultures and identities are static realities, on the one hand, or folklore, on the other. Too often, in fact, misinterpreted intercultural education is conditioned by an allegorical, essentialist and relativistic vision of glorification of cultural differences as such, rather than by a constructivist view of cultural diversity and the search for citizenship and social cohesion. Cultural diversity can only be conceived in terms of identity (hybrid and mutable) built socially through social interaction and not as naturally inherent (inevitable and unchanging) to a person or a group. The philosopher Kenan Malik clearly highlighted the risks of an essentialist vision of culture and identity: "Multiculturalists and forerunners of the clash of civilizations share the basic assumptions about the nature of culture, identity and difference. Both consider the main social divisions as the result of a cultural matrix or civilization. Both view cultures, or civilizations, as homogeneous entities. Both insist on the crucial importance of cultural identity and the preservation of this identity. Both perceive the conflicts emerging from non-negotiable values as unresolvable "(Malik, 2016, p. 86);

- giving visibility to the educational and cultural needs of migrants, not just to their basic needs (reception), focusing on the theme of intercultural mediation as a perspective that also takes into account the role of the socalled "second generation" of immigration. Here we consider the question of the scholastic, educational and professional orientation of this "second generation" that represents not only a crucial part of the migration phenomenon, but also a challenge for social cohesion and a factor of transformation of Italian society. Dealing with the "second generation" means first and foremost thoroughly investigating how the social composition of a country is being redefined. Italy, for example, is a country historically characterized by profound diversity, and within which regional and local identifications have played a very important role. It is with the "second generation" that some fundamental obstacles to social integration come to the fore that were hidden or postponed for first-generation immigrants, who were in a homecoming phase. In the context of immigrant populations, the very birth and socialization of the "second generation" represents a decisive moment for the awareness of their status as minorities now established in a different context from that of the original society. With them, needs arise for the definition, re-elaboration and transmission of their cultural heritage, as well as models of family education. Therefore, these young people live in a condition of "double identity" or "double belonging" and must be prevented from turning into a "double absence" (Sayad). The young people of the "second generation" are "natural cultural mediators", but there must be the conditions for their support and empowerment in schools, associations and society, starting from the juridical recognition of Italian citizenship by reforming the obsolete legislation founded on the right of blood;

- strengthen networks between schools, adult education centers, and community centers intended as connection spaces that favor critical reflection on educational practices and on the development and implementation of intercultural activities that are not only addressed to migrants and the "second generation", but to the whole population in a real intercultural perspective, first of all rethinking school and education as a privileged place for intercultural mediation. School is one of the key elements of a process of integration that connects the scholastic success of the children of immigrants, the professional and social integration of families, as well as being the "place" given to cultural differences in our society. To facilitate the transition from a situation of multiculturality, with the simple coexistence between different cultures, to an authentic situation of integration, acceptance and exchange, schools must promote meeting and favor situations of connection with others. The intercultural approach is an indispensable way to respect and value diversity in search of common values that allow us to live together. This new vision of relationships between people who belong to different cultures should modify and transform the structure of school and teaching organizations, teaching and training methods, assessment methods, relationships between teachers, pupils and families in and outside of school, and provide a perspective from which to approach knowledge and the disciplines. Intercultural education is one of the indispensable tools for facing the challenge of a multicultural society through the construction of paths of recognition of pluralism and diversity in reciprocity. In essence, it is now clear that today it is impossible to speak of integration without more consciously encouraging the goal of bringing about a new reality - an intercultural reality - within which schools, institutions and the Italian society all have to face one another.

Intercultural education requires a constant commitment in schools and at all levels of society within the framework of lifelong learning processes of individuals and communities. This approach is neither natural nor obvious and, on the contrary, represents an intentional educational project and a process that must be consciously carried out day by day and that requires attention and competence on the part of all participants. "Intercultural education is part of the great tradition of Italian democratic pedagogy and has among its main objectives social justice and equal opportunity regardless of an individual's history or origin. Intercultural strategies avoid separating individuals into 
autonomous and impermeable cultural worlds, instead promoting debate, dialogue and even mutual transformation, to make coexistence possible and to face, with the tools of pedagogy, the conflicts that may arise" (Fiorucci, Pinto Minerva, Portera, 2017: 618).

An intercultural perspective and ingenuity represent indispensable assets for an education adapted to the times, capable of educating people aware that they are living in a global and complex world, where the encounter with cultural differences is now the norm.

\section{Authors note:}

Massimiliano Fiorucci is the Head of the Department of Education, Roma Tre University, is Full Professor of General, Social and Intercultural Education. In the same Department, he is also Coordinator of CREIFOS (Center of Research on Intercultural and Development Education) (www.creifos.org) and Director of the Master program in "Intercultural Education". From 2007 to 2013 he has been coordinator of the PhD program in Education. From 2006 to 2013 he has been Secretary of the Italian Pedagogical Society (SIPED) and in 2017 he was elected as member of the SIPED Board. In January 2019 he has been appointed Vice President of CUNSF (National Conference of the Heads of Departments of Education). His research interests focus mainly on intercultural education with particular reference to the issues of intercultural mediation and migrant literature. It also deals with social pedagogy, general pedagogy, adult education, analysis of cultural needs, quality of education and education in organizations.

\section{References}

Bonifazi C. (2007). L'immigrazione straniera in Italia. Bologna: Il Mulino.

Caritas-Migrantes (2006). Immigrazione. Dossier Statistico 2006. XVI Rapporto. Roma: Idos.

Fiorucci M., Pinto Minerva F., Portera A. (editors) (2017). Gli alfabeti dell'intercultura. Pisa: ETS.

Luatti L. (a cura di) (2006). La città plurale. Trasformazioni urbane e servizi interculturali. Bologna: EMI.

Malik (2016). Il multiculturalismo e i suoi critici. Roma: Nessun dogma.

Nanni A., Fucecchi A. (2018). Dove va l'intercultura? Oltre la scuola ... la città. Brescia: Morcelliana.

Sayad A. (2002). La doppia assenza. Milano: Raffaello Cortina.

Sgritta G.B. (1993). La cittadinanza: principi, regole $e$ fatti. In "Tutela", 8, 1.

Susi F. (1995). L'interculturalità possibile. Roma: Anicia. 